\title{
Como reverter a atual situação econômica?
}

\author{
FERNANDO FERRARI-FILHO ${ }^{I}$
}

\section{Introdução}

$\mathrm{E}$ NTRE 1999, quando da implementação da política macroeconômica baseada no Novo Consenso Macroeconômico (NCM) - Regime de Metas de Inflação (RMI), metas de superávit fiscal e câmbio flexível -, e 2016, o PIB brasileiro apresentou um comportamento à la stop-and-go e cresceu, em média, $2,3 \%^{1}$ ao ano, muito abaixo dos crescimentos médios do PIB mundial e das economias emergentes, respectivamente, $3,8 \%$ e $5,7 \%$ ao ano. ${ }^{2}$ Por sua vez, ao longo do mesmo período, a inflação média anual foi da ordem de $6,8 \%,{ }^{3}$ relativamente alta para um país que adota RMI.

Os referidos resultados nos levam à seguinte questão: Por que nos últimos dezoito anos o desempenho da atividade econômica foi risível e a inflação ainda persiste em manter-se elevada, principalmente em relação ao target do RMI? ${ }^{4}$

No nosso ponto de vista, vários fatores explicam essa situação da economia brasileira: (i) inadequação do RMI para lidar com a inflação brasileira, uma vez que as características inflacionárias da nossa economia não são necessariamente de demanda; (ii) baixa relação formação bruta de capital fixo/PIB; ${ }^{5}$ (iii) volatilidade e pragmatismo das políticas monetária e fiscal, principalmente a partir de 2011; (iv) tendência de apreciação da taxa de câmbio; ${ }^{6}$ (v) desdobramentos da crise internacional, seja do subrime, seja da zona do Euro, uma vez que tais crises, ao afetarem a dinâmica do volume de comércio mundial e contribuírem para a queda dos preços das commodities agrícolas e minerais, impactaram negativamente as exportações brasileiras; (vi) implementação, a partir de 2009, de políticas macroeconômicas voltadas basicamente para o consumo privado que, infelizmente, a médio e longo prazos não conseguiram sustentar a dinâmica de crescimento $;^{7}$ e (vii) desequilíbrios fiscais e crescimento da dívida pública, limitando, assim, a operacionalidade contracíclica da política fiscal.

O objetivo do presente artigo é apresentar uma proposição econômica keynesiano-institucionalista para a economia brasileira que seja capaz de assegurar estabilização econômica, entendida como crescimento econômico sustentável, estabilidade monetária e equilíbrios fiscal e externo. Para tanto, as atenções centrar-se-ão nas políticas macroeconômicas e nas reformas estruturais.

Além desta introdução, a seção seguinte apresenta nossa proposição e a última conclui. 


\section{Uma proposição keynesiano-institucionalista para a economia}

Inicialmente, em que consiste, sucintamente, os approaches keynesiano e institucionalista? John Maynard Keynes, em sua principal obra, The General Theory of Employment, Interestand Money (1936/2007), apresenta o modus operandi de uma economia monetária da produção, que é inerentemente instável, bem como propõe medidas econômicas que mitiguem as flutuações cíclicas dos níveis de produto e emprego e reduzam as desigualdades da renda e da riqueza. Os institucionalistas apresentam uma "teoria econômica evolucionária”, em que instintos, hábitos e instituições influenciam a trajetória (path dependence) do sistema econômico. ${ }^{8}$

Pois bem, tendo como referência os approaches keynesiano e institucionalista, visando à estabilização econômica, conforme definição anterior, a ideia é que sejam criadas as condições macroeconômicas e estruturais favoráveis para a expansão da demanda agregada, a estabilização dos preços e os equilíbrios fiscal e externo.

No que diz respeito à expansão dos níveis de produto e emprego, operacionalização de políticas monetária, fiscal e cambial, objetivando sinalizar expectativas otimistas para os empresários tomarem decisões de investimento - o que Keynes (1936/2007) chamou de animal spirits - e parcerias público-privadas são importante para que a formação bruta de capital fixo/PIB cresça da média atual de $17,5 \%$ para $25 \%$. $^{9}$

Mais especificamente:

- A política monetária, por um lado, não pode ser voltada unicamente para controlar o processo inflacionário, mas, também, deve se preocupar em dinamizar a atividade econômica e o nível de emprego. Por outro lado, é pertinente a adoção de medidas macroprudenciais para mitigar riscos financeiros e limitar a expansão desenfreada do crédito;

- A política fiscal não deve ser conduzida simplesmente para garantir o serviço da dívida pública a qualquer custo, mas tem que ter como objetivos expandir o investimento público e dinamizar os programas sociais. Assim sendo, por um lado, alguma combinação entre juros baixos e controle sobre o gasto corrente é necessária para elevarem o investimento público e os gastos sociais. Por sua vez, a sustentabilidade da dívida pública em longo prazo pode ser obtida pela divisão do orçamento publico, conforme proposto por Keynes (1980), quais sejam, orçamento ordinário relacionado às despesas correntes e orçamento de capital para as despesas de investimento público. O orçamento ordinário deve estar sempre em equilíbrio ou preferencialmente superavitário, ao passo que o orçamento de capital pode apresentar, temporariamente, desequilíbrios, de modo a viabilizar os investimentos públicos; ${ }^{10}$

- Taxa de câmbio competitiva é um dos fatores determinantes do crescimento da economia, em particular economias em processo de desen- 
volvimento, tai como a brasileira. Para tanto, a implementação de um regime de câmbio flutuante administrado, visando à manutenção de uma Taxa de Câmbio Real Efetiva (TCRE) estável e competitiva, seja para assegurar a lucratividade das atividades dos bens comercializáveis, seja para prover incentivos para as firmas investirem e expandirem a produção e o emprego, é desejável (Frenkel, 2006). Indo nessa direção, Ferrari-Filho e Paula (2012) propõem a criação de um Fundo de Estabilização Cambial, a ser utilizado pelo Tesouro Nacional para comprar e vender divisas com vistas a influenciar a TCRE. Concomitantemente, a adoção de controle de capitais é fundamental para manter relativamente estável o valor da TCRE e garantir a autonomia da política monetária. ${ }^{11}$

No que diz respeito à estabilidade de preços, antes de tudo, é necessário ter ciência de que, conforme argumentam Arestis, Ferrari-Filho e Paula (2011) e Modenesi e Araújo (2013), pelo fato de a inflação brasileira não ser necessariamente de demanda, o RMI não tem tido sucesso para não somente manter baixa a inflação, mas, principalmente, trazê-la para o target. Os referidos autores mostram que a dinâmica inflacionária brasileira está associada preponderantemente a características de cost-push. Exemplificando, em 2015 o IPCA, índice oficial da inflação brasileira, atingiu 10,7\%, devido ao efeito pass-through da desvalorização cambial $^{12}$ e ao reajuste preços públicos e administrados. Ademais, outro componente importante da atual inflação brasileira é a indexação de preços e salários e dos contratos em geral. Nesse particular, é importante mencionar que um fator adicional do nosso processo inflacionário tem sido a política de aumento real do salário mínimo, pois a recuperação do poder de compra do salário mínimo pressiona duplamente a inflação de serviços, seja pelo lado da demanda, em função do aumento na renda de segmentos de baixa e média renda, seja pelo lado da oferta, em função dos efeitos de aumentos salariais.

Assim sendo, o controle do processo inflacionário passa pela estabilização e, portanto, menor volatilidade da taxa de câmbio, bem como pela desindexação dos preços, dos salários e dos contratos, especialmente os financeiros vinculados às Letras Financeiras do Tesouro, fundamental para deixarmos a memória inflacionária para trás. Em relação à desindexação, a adoção de uma política de rendas como alguma "âncora” para preços e salários é aconselhável. Concomitantemente, a expansão da atividade econômica e da capacidade produtiva é essencial para que não ocorram eventuais desequilíbrios entre demanda e oferta. Para tanto, as estabilidades monetária e fiscal são importantes. Alternativamente à continuidade do RMI, não é demais ressaltar que tem surgido propostas interessantes que sugerem que a política monetária não seja operacionalizada unicamente em conformidade com o referido regime, mas, sim, em um contexto que incorpore também metas de crescimento do PIB nominal. ${ }^{13}$

Em relação ao equilíbrio do setor público, ao invés do Novo Regime Fiscal, PEC do Teto dos Gastos Públicos proposta pelo governo Michel Temer e 
aprovada no Congresso Nacional, cujo reajuste nominal, pela inflação passada, dos gastos públicos correntes "engessa" a política fiscal dos cinco próximos governos, o que torna inócua a política fiscal, o ideal é se estabelecer uma meta fiscal ajustada ao ciclo econômico. Por quê? Porque ao associar os gastos públicos correntes à dinâmica do PIB, a política fiscal passa a exercer sua função contracíclica. ${ }^{14}$ Concomitantemente, é fundamental a redução da taxa Selic para que o custo de rolagem da dívida pública não pressione o déficit público e tampouco infle a referida dívida. Ademais, cabe ressaltar que as próprias receitas públicas tendem a se recuperar na medida em que a atividade econômica seja mais pujante e sustentável.

Quanto ao equilíbrio do balanço de pagamentos, de maneira que o país não fique dependente de "poupança externa", além de uma TCRE, são necessárias: (i) política industrial que, por um lado, dinamize o volume de comércio exterior, através sobretudo do aumento da competitividade da estrutura produtiva (Kupfer, 2005) e, por outro, vise à atração de investimento direto estrangeiro, capaz de alterar as elasticidades-renda das exportações e das importações; e (ii) política tarifária ativa e instrumentos não tarifários, tais como políticas de crédito e financiamento, para que a política industrial reestruture as exportações e substitua as importações. Além do mais, políticas comerciais estratégicas e mecanismos eficientes de regulamentação e de estímulos para setores industriais dinâmicos que operem em escala internacional, sob condições de retornos crescentes que gerem externalidade tecnológica, são essenciais para expandir as exportações (Baumann, 2002).

Por fim, reformas estruturais ${ }^{15}$ são imprescindíveis para que, segundo Hodgson (2002), se tenha a sinalização de um "continuous process" de reestruturação do capitalismo que não o faça ser sempre dependente do mecanismo automático das "leis" de mercado. Para tanto, para que elas sejam implementadas, é necessária a redefinição do papel do Estado na economia brasileira, através da reconstrução dos mecanismos de coordenação desmontados ao longo dos anos 1990. Em outras palavras, o Estado brasileiro tem que voltar a exercer suas funções de planejador, regulador e indutor da atividade econômica.

\section{À guisa de conclusão}

A proposição apresentada na seção anterior, com inspiração na abordagem keynesiano-institucionalista, mostra que a estabilização da economia brasileira depende tanto da adoção de um mix de políticas macroeconômicas quanto da implementação de reformas estruturais que sejam capazes de criar um ambiente institucional favorável às decisões de gastos de investimento e de recuperar a capacidade do Estado de intervir na economia.

Ademais, entendemos que nossa proposta "concilia" duas estratégias de desenvolvimento para a economia brasileira que podem ser vistas, aparentemente, como opostas: social-desenvolvimentista e novo desenvolvimentista, cujas dinâmicas de crescimento são, respectivamente, o mercado doméstico e o setor 
externo. ${ }^{16}$ Por quê? Porque, crescimento econômico sustentável e estabilidade de preços são fundamentais para inclusão social e distribuição de renda, equilíbrio e responsabilidade fiscal são requisitos para solvência da dívida pública e, por conseguinte, operacionalização de políticas fiscais contracíclicas e equilíbrio de balanço de pagamentos elimina as restrições externas ao crescimento.

\section{Notas}

1 Para o ano 2016 levou-se em consideração, com base no último Focus de 26/12 do Banco Central do Brasil (BCB), uma estimativa de queda do PIB da ordem 3,5\%.

2 Taxas médias calculadas pelo autor com base nas informações estatísticas do International Monetary Fund (IMF, 2017).

3 Taxa média calculada pelo autor baseada nas informações estatísticas do Ipeadata (2017).

4 Nesse particular, é importante ressaltar que entre 1999 e 2016 a inflação anual ficou abaixo do target somente em quatro anos, bem como as metas de inflação não foram atingidas em cinco anos.

5 Entre 1999 e 2016, a relação formação bruta de capital fixo/PIB foi, em média, da ordem de $17,5 \%$ ao ano. Taxa média calculada pelo autor tendo com base as informações estatísticas do Ipeadata (2017) e BCB (2017).

6 Uma análise sobre a tendência e os desdobramentos da valorização cambial brasileira pode ser encontrada em Bresser-Pereira (2013) e Nassif, Feijó e Araújo (2015).

7 Por exemplo, Ferrari-Filho e Fonseca (2015) mostram, a partir de uma análise teórica sobre regimes de crescimento, as limitações do recente crescimento econômico brasileiro alicerçado em um regime à la wage-led.

8 Para maiores detalhes sobre a concepção institucionalista, ver Ferrari-Filho e Conceição (2005).

9 Por que 25\%? Primeiro, porque durante os anos 1970, período no qual o crescimento econômico brasileiro alcançou as maiores taxas de sua história, a relação formação bruta de capital fixo/PIB era ao redor de $25 \%$. Segundo, porque a taxa media da relação formação bruta de capital fixo/PIB dos principais países emergentes é da ordem de $25 \%$ (média calculada pelo autor a partir dos dados estatísticos do IMF (2017)).

10 Uma proposta a ser considerada é a apresentada por Silva e Pires (2006), que sugerem uma mudança na prática da política fiscal adotada no Brasil através de uma meta fiscal que exclua os investimentos públicos do cálculo do superávit primário. Em outras palavras, os autores propõem trocar o conceito de superávit primário pelo conceito de "poupança em conta corrente do governo", o que permitiria o Estado aumentar os investimentos públicos.

11 Para uma análise teórica e empírica sobre controle de capitais ver Sicsú e Ferrari-Filho (2006).

12 A desvalorização cambial em 2015 foi da ordem de 50,0\%.

13 Segundo Sumner (2014), metas de crescimento do PIB nominal levam a uma inflação razoavelmente baixa ao longo do tempo, bem como minimiza o ciclo econômico, tornando os momentos de aquecimento e desaquecimento da economia menos severos. 
14 Nesse particular, um estudo do Banco Interamericano de Desenvolvimento (BID, 2012 ) analisa os impactos positivos dos multiplicadores fiscais na economia brasileira decorrentes de políticas contracíclicas.

15 Por exemplo, reforma tributária que tenha como princípios a eficiência (racionalização tributária) e a equidade da tributação (justiça fiscal) e reforma previdenciária que solucione tanto o desequilíbrio de curto prazo quanto o bottleneck de longo prazo decorrente da perda do bônus demográfico do Brasil, entre outras.

16 Para maiores detalhes sobre as estratégias social-desenvolvimentista e novo-desenvolvimentista ver, respectivamente, Bastos (2012) e Bresser-Pereira (2016).

\section{Referências}

ARESTIS, P.; FERRARI-FILHO, F.; PAULA, L. F. Inflation targeting in Brazil. International Review of Applied Economics, v.25, n.2, p.127-48, 2011.

BANCO CENTRAL DO BRASIL Focus - Relatório de Mercado, 26/12. 2016. Disponível em: <http://www.bcb.gov.br>. Acesso em: 12 jan. 2017.

. Séries Temporais. 2017. Disponível em: <http://www.bcb.gov.br>. Acesso em: 12 jan. 2017.

BANCO INTERAMERICANO DE DESENVOLVIMENTO (BID). Multiplicadores Fiscais no Brasil. Brasília: BID, 2012.

BASTOS, P. P. Z. A economia política do novo desenvolvimentismo e do social desenvolvimentismo. Economia e Sociedade, v.21, número especial, p.779-810, 2012.

BAUMANN, R. Os desafios da exportação. In: CASTRO, A. C. (Org.) Desenvolvimento em debate: painéis do desenvolvimento brasileiro, Rio de Janeiro: BNDES-Mauad, 2002. v.1, p.105-30.

BREESER-PEREIRA, L. C. The value of the exchange rate and the Dutch disease. Revista de Economia Politica, v.33, n.3(133), p.371-87, jul.-ago.-set. 2013.

. Teoria Novo-Desenvolvimentista: uma síntese. 2016. Disponível em: <http:// www.bresserpereira.org.br/papers/2016/311-Teoria-Novo-desenvolvimentista-CCF. pdf>. Acesso em: 12 jan. 2017.

FERRARI FILHO, F.; CONCEIÇÃO, O. A. C. The concept of uncertainty in Post-Keynesian theory and in Institutional Economics. Journal of Economic Issues, v.39, n.3, p.579-94, September 2005.

FERRARI-FILHO, F.; FONSECA, P. C. D. Which developmentalism? A Keynesian-Institutionalist proposal. Review of Keynesian Economics, v.3, n.1, p.90-107, Spring 2015.

FERRARI-FILHO, F.; PAULA, L. F. Avaliação do regime cambial brasileiro pós-1999: análise crítica e prospectiva. In: OREIRO, J. L.; PAULA, L. F.; BASÍLIO, F. (Org.) Macroeconomia do desenvolvimento: ensaios sobre restrição externa, financiamento e política macroeconômica. Recife: Editora da UFPE, 2012. p.317-54.

FRENKEL, R. An alternative to inflation targeting in Latin America: macroeconomic policies focused on employment. Journal of Post Keynesian Economics, v.28, n.4, p.57391, 2006. 
HODGSON, G. M. The evolution of institutions: an agenda for the future theoretical research. Constitutional Political Economy, v.13, p.11-127, 2002.

INTERNATIONAL MONETARY FUND (IMF). Data and Statistics. 2017. Disponível em: <http://www.imf.org>. Acesso em: 12 jan. 2017.

IPEADATA. Séries Históricas. 2017. Disponível em: <http://www.ipeadata.gov.br>. Acesso em: 12 jan. 2017.

KEYNES, J. M. Activities 1940-1946: Shaping the Post-War world - employment and commodities (The Collected Writings of John Maynard Keynes, XXVII). London: Macmillan, 1980.

cmillan, 2007.

. The General Theory of Employment, Interest and Money. London: Palgrave Ma-

KUPFER, D. Política industrial, infraestrutura e inovação. In: CAVALCANTI, B.; RUEDIGER, M.; SOBREIRA, R. (Org.) Desenvolvimento e construção nacional: política econômica. Rio de Janeiro: FGV; Konrad Adenauer, 2005. p.129-44.

MODENESI, A.; ARAÚJO, E. C. Price stability under inflation targeting in Brazil: an empirical analysis of the monetary policy transmission mechanism based on a VAR model (2000-2008). Investigación Económica, v.LXXII, n.283, p.99-133, 2013.

NASSIF, A.; FEIJÓ, C.; ARAÚJO, E. Overvaluation trend of the Brazilian currency in the 2000s: empirical estimation. Revista de Economia Politica, v.35, n.1(138), p.3-27, jan.-fev.-mar. 2015.

SICSÚ, J.; FERRARI-FILHO, F. (Org.). Câmbio e controle de capitais: avaliando a eficiência de modelos macroeconômicos. Rio de Janeiro: Elsevier, 2016.

SILVA, A. M.; PIRES, M. C. Dívida pública, poupança em conta corrente do governo e superávit primário: uma análise de sustentabilidade. Texto para Discussão IPEA, n.1196, junho, 2006.

SUMNER, S. B. Nominal GDP targeting: a simple rule to improve Fed performance. Cato Journal, v.34, n.2, p.315-37, Spring-Summer, 2014.

RESUMO - O presente artigo objetiva apresentar uma proposição econômica keynesiano-institucionalista para a economia brasileira que seja capaz de assegurar crescimento econômico sustentável, estabilidade monetária e equilíbrios fiscal e externo.

PALAVRAS-CHAVES: Economia brasileira, Estagflação e proposição keynesiano-institucionalista. ABSTRACT - This paper aims to present a Keynesian-institutionalist economic proposal to ensure sustainable economic growth for the Brazilian economy, combined with monetary stability, and fiscal and external equilibrium.

KEYWORDS: Brazilian economy, Stagflation and Keynesian-institutionalist proposal.

Fernando Ferrari-Filho é professor titular da Faculdade de Ciências Econômicas, Universidade Federal do Rio Grande do Sul, e pesquisador nível 1 do CNPq. @ - ferrari@ufrgs.br Recebido em 12.2.2017 e aceito em 20.2.2017.

I Faculdade de Ciências Econômicas, Universidade Federal do Rio Grande do Sul, Porto Alegre / Rio Grande do Sul, Brasil. 